\title{
SISTEM INFORMASI PENDATAAN PEMESANAN TIKET BUS LINTAS JAWA PADA PT. SINAR JAYA MEGAH LANGGENG
}

\author{
Rescal Castro ${ }^{1}$, Putri Dina Mardika ${ }^{2}$ \\ Program Studi Teknik Informatika, Fakultas Teknik dan Ilmu Komputer, \\ Universitas Indraprasta PGRI \\ Jalan Raya Tengah No 80, Kelurahan Gedong, Pasar Rebo, Jakarta Timur \\ rescalcastro2206@gmail.com ${ }^{1}$, putridinamar@gmail.com²
}

\begin{abstract}
Abstrak
Tujuan penelitian adalah membangun suatu sistem guna meminimalisir kesalahan saat proses pendataan pada Pemesanan Tiket Bus Lintas Jawa. Yang nantinya diharapkan dapat menggantikan sistem lama yang masih manual sehingga pelayanan terhadap konsumen bisa lebih maksimal. Dalam melakukan penelitian ini peneliti menggunakan metode yaitu metode air terjun (waterfall) dalam proses pengumpulan data yang dibutuhkan dengan studi lapangan melalui observasi dan wawancara. Serta melakukan studi kepustakaan untuk mendapatkan data dan informasi yang lebih akurat. Berdasarkan analisa data yang telah dilakukan, diperoleh kesimpulan bahwa PT. Sinar Jaya Megah Langgeng perlu adanya pembaruan berupa sistem yang terintegrasi sistem informasi sehingga dapat memudahkan proses pendataan pemesanan baik pada penumpang maupun admin tiket serta dapat meningkatkan kinerja Admin tiket menjadi lebih baik kedepannya.
\end{abstract}

Kata Kunci: Sistem informasi, Pendataan, Pemesanan, Tiket, Mysql.

\begin{abstract}
The purpose of this research is to build a system to minimize errors during the data collection process on the Trans Java Bus Ticket Booking. Which later is expected to replace the old system which is still manual so that service to consumers can be maximized. In conducting this research, the researcher used a method, namely the waterfall method in the process of collecting the required data with field studies through observation and interviews. As well as conducting a literature study to obtain more accurate data and information. Based on the data analysis that has been done, it can be concluded that PT. Sinar Jaya Megah Langgeng needs an update in the form of an integrated system of information systems so that it can facilitate the ordering process for both passengers and ticket admins and can improve ticket admin performance for the better in the future.
\end{abstract}

Keywords: Information systems, Data Collection, Ordering, Tickets, Mysql.

\section{PENDAHULUAN}

Pendataan pemesanan tiket bus yang terintegrasi Sistem Informasi merupakan hal penting dalam mengolah data agar data tersebut terorganisir dengan baik. Karena Dalam satu hari ada puluhan bahkan ratusan customer atau calon penumpang yang melakukan pemesanan tiket bus. Menurut (Rahmat \& Octaviano, 2016) tiket adalah suatu dokumen perjalanan yang dikeluarkan oleh suatu perusahaan yang berisi rute, tanggal, harga, data penumpang yang digunakan untuk melakukan suatu perjalanan". PT. Sinar Jaya Megah Langgeng adalah salah satu perusahaan yang bergerak di bidang Ottobus atau penyedia jasa perjalanan menggunakan bus. Belum adanya sistem pendataan pemesanan tiket bus yang terintegrasi sistem informasi sebelumnya di PT. Sinar Jaya Megah Langgeng, yang mungkin saja hal ini dapat menyebabkan kesalahan dalam pendataan pemesanan tiket bus. Oleh karena dengan adanya aplikasi ini berguna untuk Meminimalkan kesalahan dalam pendataan pemesanan tiket bus, sehingga dapat lebih mudah dalam melakukan input data-data pelanggan menggunakan satu aplikasi. Berdasarkan uraian diatas maka peneliti tertarik untuk melakukan penelitian yang berjudul "Sistem Informasi Pendataan Pemesanan Tiket Bus Lintas Jawa Pada PT. Sinar Jaya Megah Langgeng Berbasis Desktop”. 


\section{PENELITIAN RELEVAN}

Pada awal penelitian peneliti telah melakukan beberapa pengamatan mengenai aturan bisnis yg ada di PT. Sinar Jaya Megah Langgeng Belum adanya sistem pendataan pemesanan tiket bus yang terintegrasi sistem informasi sebelumnya di PT. Sinar Jaya Megah Langgeng, yang mungkin saja hal ini dapat menyebabkan kesalahan dalam pendataan pemesanan tiket bus. Dengan demikian ada beberapa penelitian yang menjadi acuan peneliti untuk membuat sistemn informasi tersebut antara yaitu :

Penelitian yang pertama diambil dari jurnal dengan judul Perancangan Sistem Administrasi Pemesanan Tiket Bus Pariwisata PT Fitri Trans Abadi dengan hasil penelitian Perancangan sistem administrasi pemesanan tiket bus pariwisata pada PT Fitri Trans Abadi menjadikan operasional perusahaan lebih efektif, cepat, dan efisien dalam pengolahan datanya. Sistem administrasi yang peneliti buat hanya sebagai penunjang proses operasional untuk mengefisienkan waktu dan keakuratan data setidaknya dapat mambantu petugas dalam mengelola data pemesanan unit kendaraan (Nurkholis dkk, 2021).

Penelitian yang kedua diambil dari jurnal dengan judul Penggunaan Model Waterfall Dalam Pembuatan Aplikasi Pemesanan Tiket Bus dengan hasil penelitian Dengan dibuatkan sebuah sistem yang terintegrasi sistem informasi Mempermudah serta mengefisiensikan dan mengefektifkan waktu dalam transaksi penjualan tiket bus, Mengurangi masalah human error dalam perhitungan penelitian stok tiket beserta jadwal keberangkatannya dan laporan keuangan sehingga dapat meningkatkan akurasi data. Serta Menyimpan data-data PO. Lorena ke dalam basis data yang terintegrasi (Kustian, 2019).

\section{METODE PENELITIAN}

Metode penelitian yang peneliti gunakan adalah metode air terjun (waterfall) yaitu metode penelitian berdasarkan pada fakta dan menggunakan Analisa Kebutuhan, Studi Kepustakaan, Perancangan Sistem, Desain Sistem, Penulisan Kode Program, Pengujian Program dan Evaluasi dan Penulisan Laporan. Menurut (Yunindra, 2017) metode waterfall merupakan salah satu metode dalam SDLC yang mempunyai ciri khas pengerjaan yaitu setiap fase dalam waterfall harus diselesaikan terlebih dahulu sebelum melanjutkan ke fase selanjutya

Dalam tugas akhir ini peneliti memiliki bentuk data teks, sehingga teknik pengumpulan data yang peneliti gunakan yaitu teknik pengumpulan data kualitatif. Metode pengumpulan data yang dilakukan untuk mendapatkan data-data serta informasi untuk mendukung penyempurnaan hasil dari penelitian ini antara lain :

\section{Studi Lapangan}

\section{a. Observasi}

Salah satu pendekatan untuk memperoleh informasi adalah dengan terjun langsung ke lapangan. Dalam hal ini peneliti mempelajari dan mengamati secara langsung bagaimana proses pendataan pemesanan tiket yang sedang berjalan saat ini di PT. Sinar Jaya Megah Langgeng. Menurut (Fathoni, 2012) "Observasi adalah teknik pengumpulan data yang dilakukan melalui suatu pengamatan, dengan disertai pencatatan-pencatatan terhadap keadaan atau perilaku objek sasaran".

\section{b. Wawancara}

Dimana diadakan tanya jawab kepada Finance, Admin Tiket dan salah satu penumpang bus di PT. Sinar Jaya Megah Langgeng mengenai Bagaimanakah proses pendataan pemesanan tiket bus yang berjalan. Menurut (Sugiyono, 2017) "Wawancara adalah pertemuan dua orang untuk bertukar informasi dan ide melalui tanya jawab, sehingga dapat dikonstruksikan makna dalam suatu topik tertentu".

\section{Studi Literatur}

Peneliti melakukan pengumpulan data dan informasi untuk merancang aplikasi, yaitu:

a. Mempelajari buku-buku literature mengenai analisis dan desain sebuah sistem.

b. Melihat dan mempelajari framework penanganan informasi lainnya seperti aplikasi yang akan dibuat. 
c. Mempelajari beberapa buku pemrograman yang terkait dengan Java sebagai sumber referensi tambahan mengenai bagaimana cara menganalisis dan mendesain sebuah sistem yang baik dan benar.

\section{HASIL DAN PEMBAHASAN}

\section{Use Case Diagram}

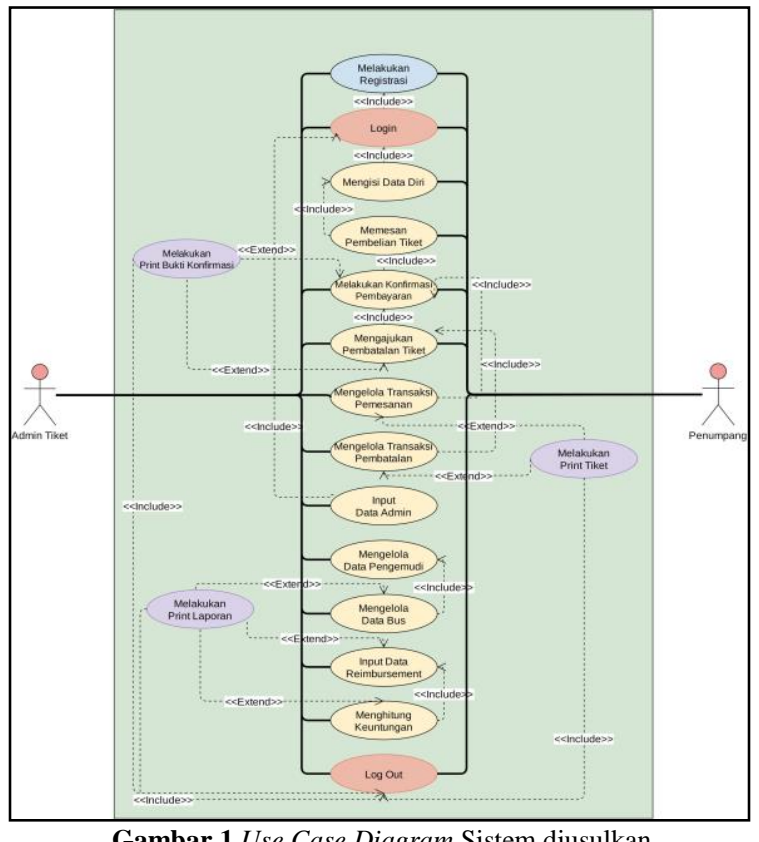

Gambar diatas merupakan use case diagram yang menunjukan setiap proses dari awal penumpang melakukan pemesanan tiket sampai proses perhitungan keuntungan dan pencetakan tiket pemesanan dan juga tiket pembatalan.

1. Registrasi

Setiap pengguna harus melakukan registrasi terlebih dulu agar bisa masuk kedalam sistem.

2. Login

Setiap pegguna bisa masuk kedalam sistem agar dapat menggunakan fungsi-fungsi yang ada didalam sistem.

3. Data diri

Fungsi Data diri hanya dapat diakses oleh pengguna dengan level Penumpang. Fungsi ini berisi tambah, ubah, hapus, batal, dan cari data penumpang.

4. Data pembelian tiket

Fungsi Data pembelian tiket hanya dapat diakses oleh pengguna dengan level Penumpang. Fungsi ini berisi tambah, ubah, hapus, batal, dan cari data pembelian tiket.

5. Konfirmasi pembayaran

Fungsi Konfirmasi pembayaran hanya dapat diakses oleh pengguna dengan level Penumpang. Fungsi ini berisi tambah, ubah, batal, cetak dan cari data Konfirmasi pembayaran.

6. Pembatalan tiket

Fungsi Pembatalan tiket hanya dapat diakses oleh pengguna dengan level Penumpang. Fungsi ini berisi tambah, batal, cetak dan cari data Pembatalan tiket.

7. Data admin

Fungsi Data admin hanya dapat diakses oleh pengguna dengan level Admin Tiket. Fungsi ini berisi tambah, ubah, hapus, batal, dan cari data admin.

8. Data pengemudi

Fungsi Data pengemudi hanya dapat diakses oleh pengguna dengan level Admin Tiket. Fungsi ini berisi tambah, ubah, hapus, batal, dan cari data pengemudi.

9. Data bus 
Fungsi Data bus hanya dapat diakses oleh pengguna dengan level Admin Tiket. Fungsi ini berisi tambah, ubah, hapus, batal, cetak dan cari data bus.

10. Transaksi pemesanan

Fungsi Transaksi pemesanan hanya dapat diakses oleh pengguna dengan level Admin Tiket. Fungsi ini berisi tambah, ubah, hapus, batal, cetak dan cari data Transaksi pemesanan.

11. Transaksi pembatalan

Fungsi Transaksi pembatalanhanya dapat diakses oleh pengguna dengan level Admin Tiket. Fungsi ini berisi tambah, ubah, hapus, batal, cetak dan cari data Transaksi pembatalan.

12. Data reimbursement

Fungsi Data reimbursement hanya dapat diakses oleh pengguna dengan level Admin Tiket. Fungsi ini berisi tambah, ubah, hapus, batal, cetak dan cari data reimbursement.

13. Data keuntungan

Fungsi Data keuntungan hanya dapat diakses oleh pengguna dengan level Admin Tiket. Fungsi ini berisi tambah, ubah, hapus, batal, cetak dan cari data keuntungan.

14. Logout

Fungsi ini digunakan untuk keluar sistem ketika telah selesai menggunakan sistem tersebut.

\section{Entity Relationship Diagram (ERD)}

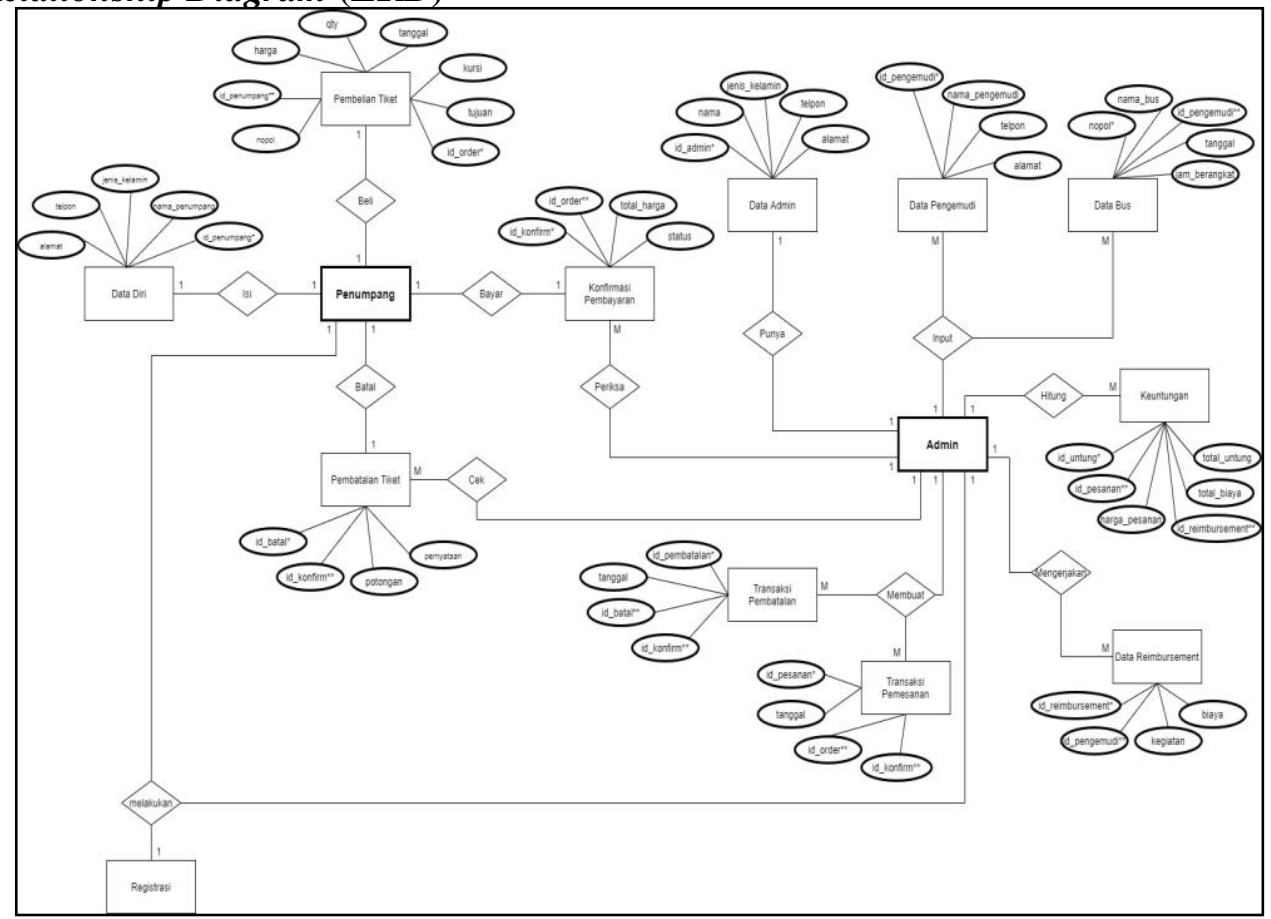

Gambar 2 ERD (Entity Relationship Diagram)

Gambar diatas merupakan bentuk dari entity relationship diagram dari sebuah alur data yang akan mengalir dari satu proses ke proses berikut nya hingga menjadi sebuah data yang dapat digunakan untuk melakukan pemesanan dan pendataan pemesanan tiket yang dibutuhkan oleh PT. Sinar Jaya Megah Langgeng. 


\section{Tampilan Aplikasi}

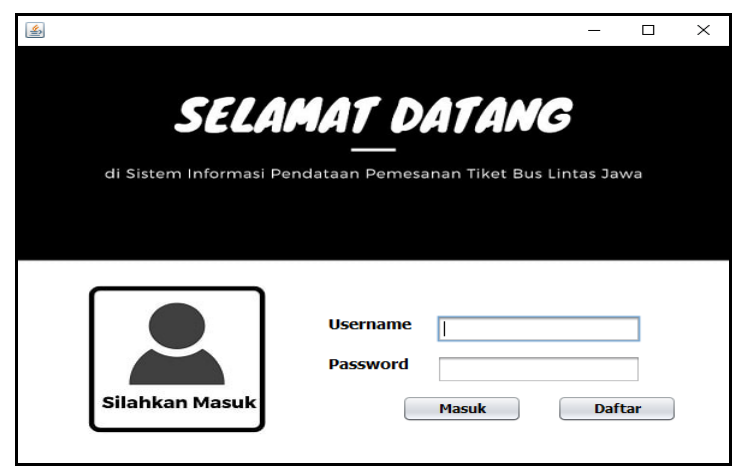

Gambar 3. Tampilan Login

Pada halaman login ini menampilkan form untuk masuk ke aplikasi.

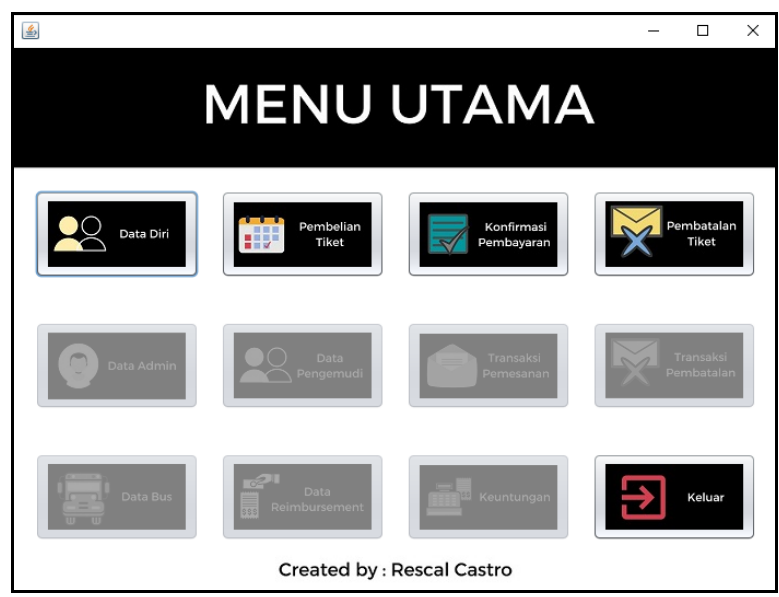

Gambar 4. Tampilan Menu Utama

Pada tampilan utama terdapat beberapa menu yang dapat di gunakan seperti data diri, pembelian tiket, konfimasi pembayaran, pembatalan tiket, data admin, data pengemudi, data bus,data reimbursement, data keuntungan, transaksi pemesanan dan transaksi pembatalan.

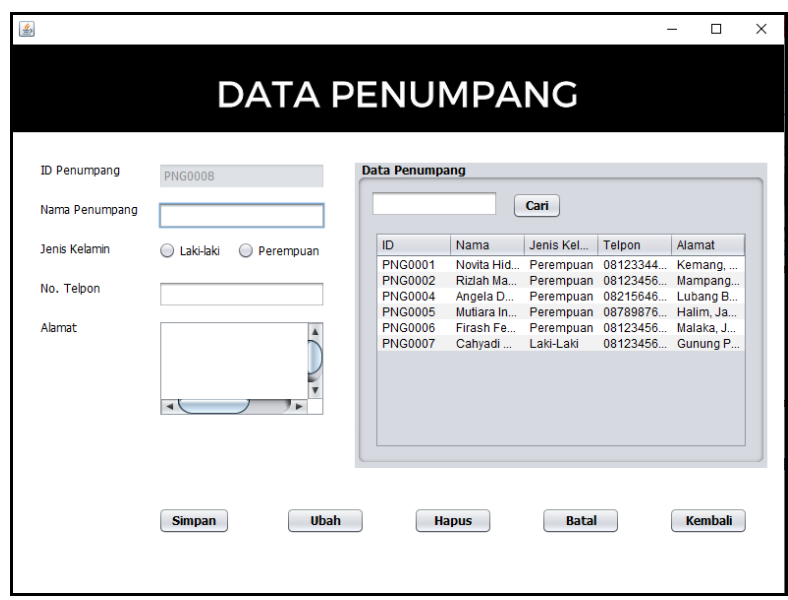

Gambar 5. Tampilan Input Data Diri

Pada gambar diatas adalah halaman untuk menambahkan / menyimpan data penumpang. 


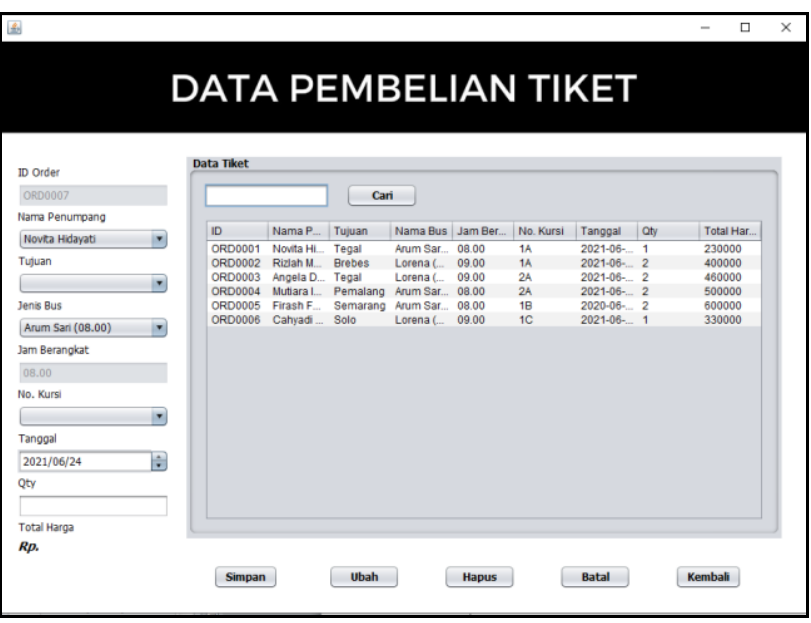

Gambar 6. Tampilan Input Data Pembelian Tiket

Pada gambar diatas adalah halaman untuk menentukan tujuan dan jadwal keberangkatan yang hendak dipilih oleh calon penumpang.

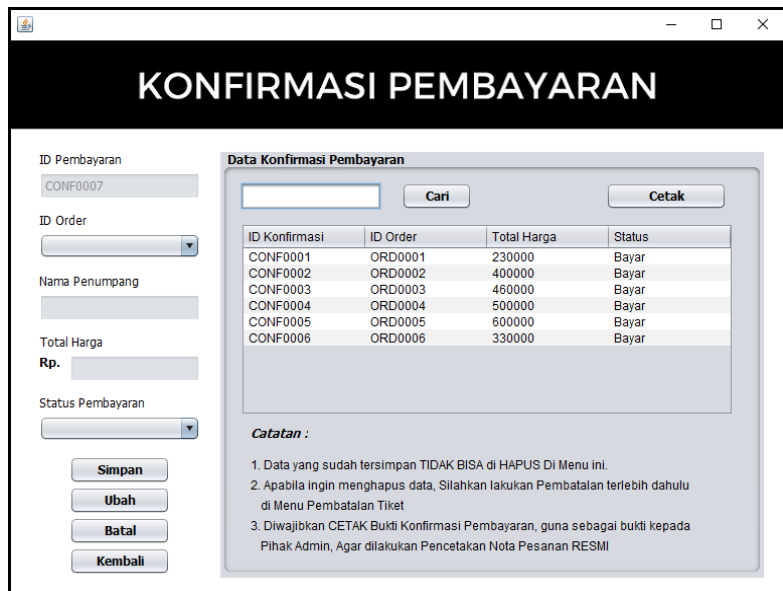

Gambar 7. Tampilan Input Data Konfirmasi Pembayaran

Pada gambar diatas adalah halaman untuk melakukan konfirmasi pembayaran dan mencetak bukti konfirmasi pembayaran.

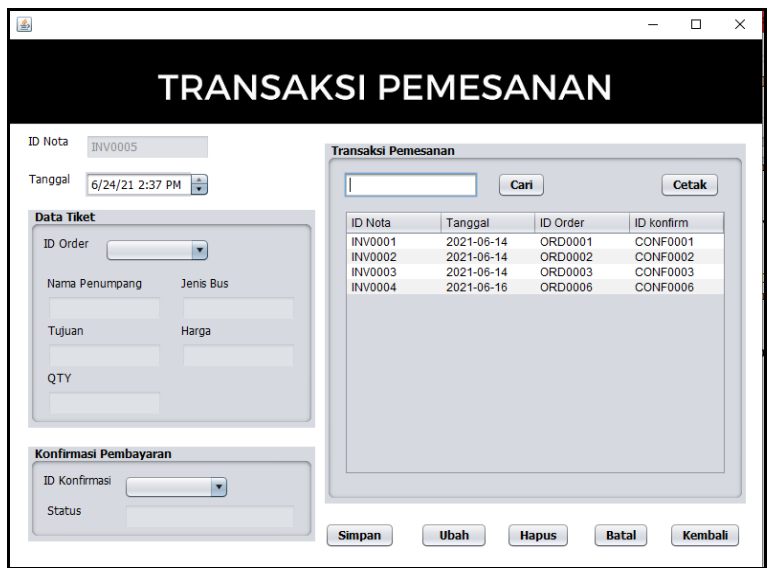

Gambar 8. Tampilan Input Transaksi Pemesanan

Pada gambar diatas adalah halaman untuk menarik data pemesanan tiket yang sebelum nya sudah diisi oleh calon penumpang pada menu sebelumnya dan cetak tiket pemesanan. 


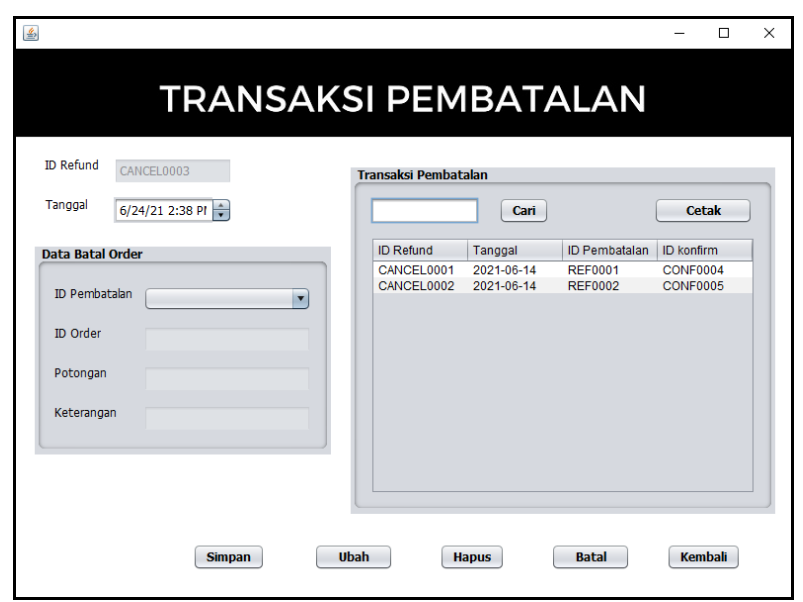

Gambar 9. Tampilan Input Transaksi Pembatalan

Pada gambar diatas adalah halaman untuk menarik data pembatalan tiket yang sebelum nya sudah diisi oleh calon penumpang pada menu sebelumnya dan cetak tiket pembatalan.

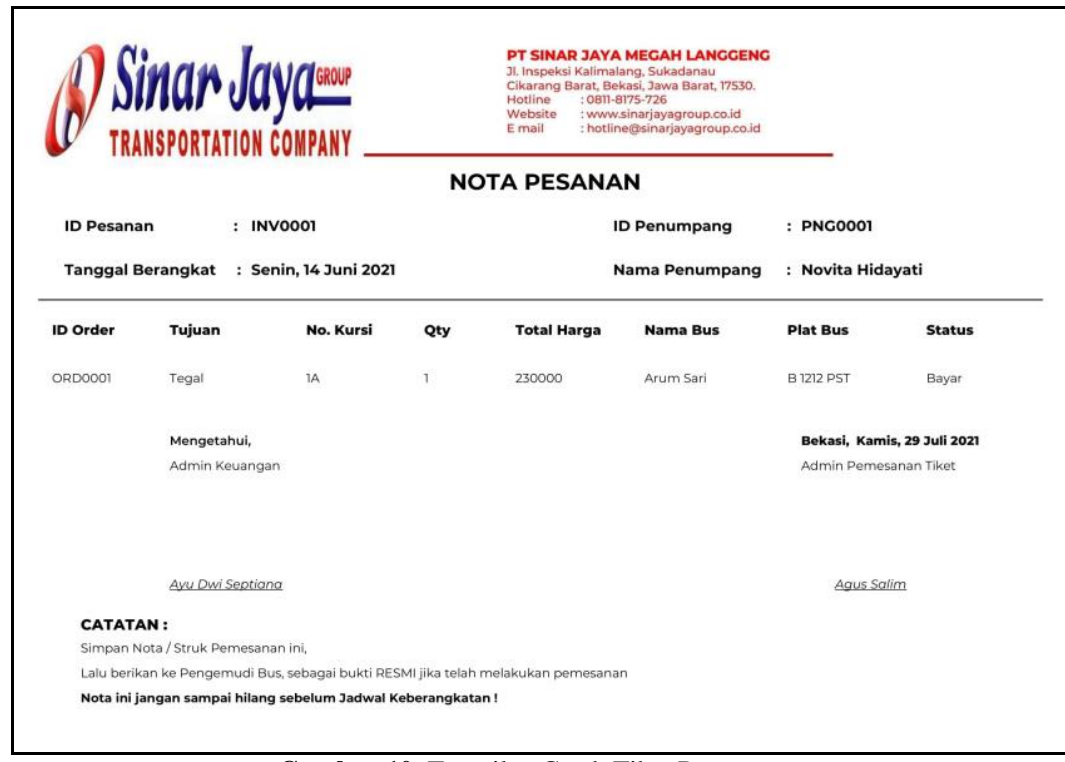

Gambar 10. Tampilan Cetak Tiket Pemesanan

Pada gambar diatas adalah tampilan cetak tiket pemesanan yang dilakukan oleh admin tiket sesuai dengan data yang ingin dicetak. 


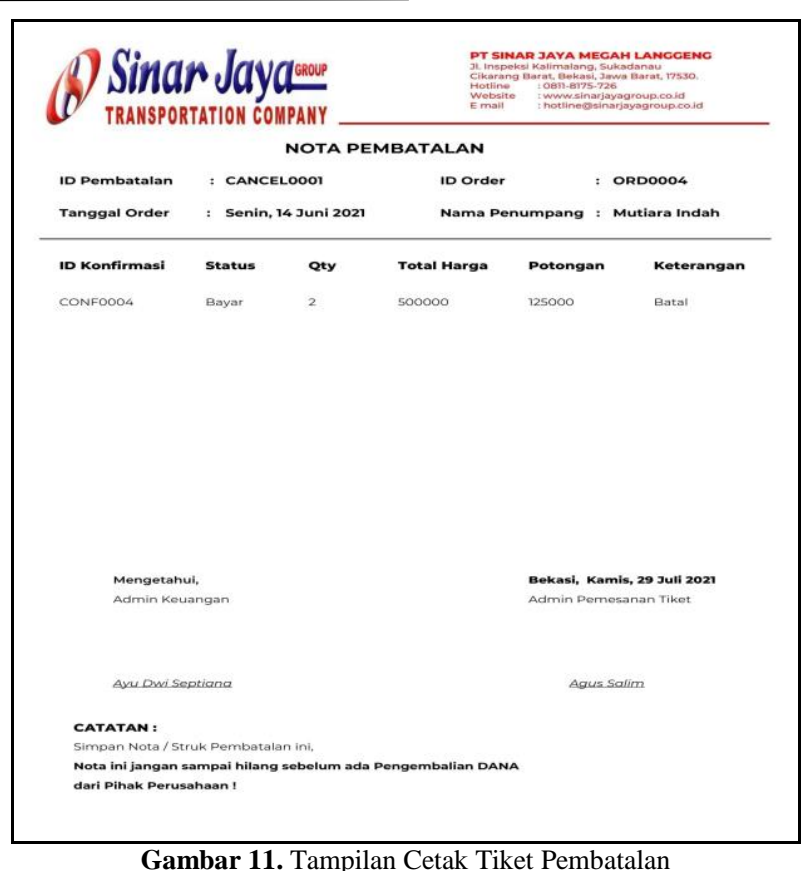

Pada gambar diatas adalah tampilan cetak tiket pembatalan yang dilakukan oleh admin tiket sesuai dengan data yang ingin dicetak.

\section{SIMPULAN}

Dengan dibuatnya Sistem Informasi Pendataan Pemesanan Tiket Bus Lintas Jawa Pada PT. Sinar Jaya Megah Langgeng, semua kegiatan yang berhubungan dengan pendataan pemesanan tiket bus tidak lagi menggunakan Microsoft Excel, tetapi menggunakan media berupa aplikasi yang terintergrasi sistem informasi.

1. Dengan adanya sistem pendataan pemesanan tiket bus yang terintegrasi sistem informasi yang berjalan di PT. Sinar Jaya Megah Langgeng menjadi lebih baik dari pada sebelumnya dalam pengolahan data baik penumpang maupun admin, dan baik dalam proses transaksi pemesanan maupun transaksi pembatalan.

2. Dengan adanya sistem ini memudahkan proses penyimpanan baik data maupun laporan yang telah diinput lebih terorganisir dengan baik secara tempat, bentuk dan keamanannya.

3. Dengan adanya sistem ini memudahkan proses pengunduhan laporan secara otomatis sehingga dapat menyajikan data-data pemesanan tiket bus dengan baik dan periodik.

\section{DAFTAR PUSTAKA}

Fathoni, Abdurahmat. (2012). Metodologi Penelitian \& Teknik Penyusunan Skripsi. Jakarta: Penerbit PT Rineka Cipta.

Hendra Kurniawan, Eri Mardiani, \& N. R. (2011). Aplikasi penjualan dengan program Java Netbeans, Xammp, dan iReport. Elex Media Komputindo.

Julianti, M. R., Dzulhaq, M. I., \& Subroto, A. (2019). Sistem Informasi Pendataan Alat Tulis Kantor Berbasis Web pada PT Astari Niagara Internasional. Jurnal Sisfotek Global, 9(2), 92-97.

Kustian, Nunu. (2019). Penggunaan Model Waterfall dalam Pembuatan Aplikasi Pemesanan Tiket Bus. String(Satuan Tulisan Riset dan Inovasi Teknologi). 4(1):94

Lestanti, S., \& Susana, A. D. (2016). Sistem Pengarsipan Dokumen Guru Dan Pegawai Menggunakan Metode Mixture Modelling Berbasis Web. Antivirus: Jurnal Ilmiah Teknik Informatika, 10(2), 69-77. https://doi.org/10.35457/antivirus.v10i2.164

Puspitasari, D. (2016). Sistem Informasi Perpustakaan Sekolah Berbasis Web. Jurnal Pilar Nusa Mandiri Vol. XII, 12(2), $227-240$.

Rahmat, A. R. A., \& Octaviano, A. (2016). Aplikasi Pemesanan Tiket Bus Berbasis Web (Studi Kasus pada PO. Harapan Jaya). Jurnal Informatika Universitas Pamulang, 1(1), 1-11.

Rosad, A. M. (2019). Implementasi Pendidikan Karakter Melalui Managemen Sekolah. Tarbawi: Jurnal Keilmuan Manajemen Pendidikan, 5(02), 173. https://doi.org/10.32678/tarbawi.v5i02.2074

Sugiyono. (2017). Metode Penelitian Kuantitatif, Kualitatif, dan R\&D. Bandung: Alfabeta.

Yurindra. (2017). Software Engineering. Yogyakarta: Deepublish. 